\title{
Congenital Muscular Torticollis: An Overview
}

Antonios G Angoules $^{1 *}$, Eleni C Boutsikari² and Eleni P Latanioti ${ }^{3}$

${ }^{1}$ General Department of Essential Medical Subjects, Technological Educational Institute of Athens, Greece

${ }^{2}$ Department of Physical Therapy, Technological Educational Institute of Athens, Greece

${ }^{3}$ Physical Therapist, Athens, Greece

\begin{abstract}
Congenital Muscular Torticollis (CMT) is a congenital deformity characterized by unilateral shortening of the sternocleidomastoid muscle resulting in lateral inclination of the neck associated with contralateral torsion. It is a relatively common infantile deformity associated with typically favourable prognosis when early detected and treated. Although stretching exercises is still the most common treatment, this therapeutic approach should be applied early in younger subjects to be efficient. Surgical intervention is guaranteed before an established craniofacial asymmetry. The purpose of this is to provide an overview of the current therapeutic approaches with additional analysis of their effectiveness.
\end{abstract}

Keywords: Congenital muscular torticollis; Treatment; Manual stretching; Tenotomy; Allantoin toxine

\section{Introduction}

Congenital Muscular Torticollis (CMT) is a congenital deformity characterized by unilateral shortening of the sternocleidomastoid muscle resulting in lateral inclination of the neck associated with contralateral torsion [1] (Figure 1).

The typical clinical element is a firm mass sized between 1 to $3 \mathrm{~cm}$ which causes shortening of the sternocleidomastoid and it is normally palpable at 1 to 4 weeks of age [2]

Although thislesion has been considered as an hematoma formation, the presence of hemosiderin has not been revealed in pathological specimens of excised masses and additionally ultrasonography, and Computerized Tomography often record isoechoic or homogeneous findings [3].

Most of cases resolve within the first year after birth. Nevertheless this firm still painless fibrotic tissue in severe cases subsequently results in secondary plagiocephaly and skull and facial asymmetry [4-7].

It is a relatively common recognized infantile abnormality and its incidence varies from $0.3 \%$ to $2.0 \%$ live births [2]. CMT is recorded as is the third most common congenital musculoskeletal anomaly after dislocation of the hip and clubfoot $[1,5]$.

CMT is often associated with other congenital deformities such as

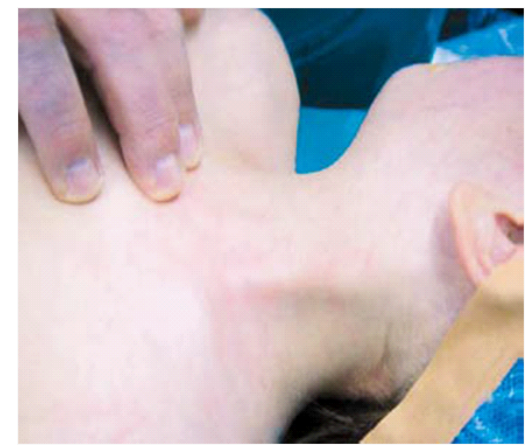

Figure 1: A contracted sternocleidomastoid muscle can be palpated in a girl with CMT. (Courtesy of Gkiokas Andreas MD, PhD, $1^{\text {st }}$ Orthopaedic Department, General Children's Hospital, 'P. \& A. Kyriakou', Athens, Greece).
Developmental Dysplasia of the Hip (DDH) with a coexistence rate estimated as high as $14.9 \%$ [8]. Other coincident lesions less frequently recorded include tibial torsion, clubfoot, calcaneovalgus foot, flexible pes planus, metatarsus adductus, and hallux valgus [9].

\section{Aetiology}

Although evidence about CTM aetiology is vague it is postulated that fetal position abnormalities, intrauterine or perinatal compartment syndrome and birth trauma ensuing a difficult delivery embody the main causes $[5,10]$.

Other possible causes encountered are hereditary and venous or arterial occlusion which may create fibrous tissue within the sternocleidomastoid $[6,11]$.

\section{Diagnosis}

Diagnosis is based mainly on past medical history and clinical examination of the infant.

A meticulous prenatal history record is essential and detects complicated labor and the coexistence of previous birth trauma such as clavicular fracture. The presence of perinatal asphyxia, jaundice, seizures, medication, gastroesophageal reflux disease (GERD) or Sandifer's syndrome are also recorded [12].

A firm painless not tender pseudotumor mass is typically palpable in the first few weeks of life $[3,13]$. This lump can affect both the sternal and clavicular parts of the muscle [14]. This endomysial mass is consisted of fibrotic issue linked with deposition of collagen and migration of fibroblasts around the atrophic sternocleidomastoid fibers [5].

Clinical examination includes evaluation of neck range of motion, and thorough neurological assessment.

*Corresponding author: Antonios G Angoules, General Department of Essential Medical Subjects, Technological Educational Institute of Athens, Greece, E-mail: antoniosangoules@yahoo.com

Received April 30, 2013; Accepted May 13, 2013; Published May 17, 2013

Citation: Angoules AG, Boutsikari EC, Latanioti EP (2013) Congenital Muscular Torticollis: An Overview. J Gen Pract 1: 105. doi: 10.4172/2329-9126.1000105

Copyright: ( 2013 Angoules AG, et al. This is an open-access article distributed under the terms of the Creative Commons Attribution License, which permits unrestricted use, distribution, and reproduction in any medium, provided the original author and source are credited. 
The type of deformation is also investigated, as well as the combination of flexion and rotation, whether the deformation is rigid or flexible, and whether it can be corrected by the child itself $[12,14,15]$.

Associated congenital musculoskeletal conditions i.e. hip dysplasia is also investigated.

Ophthalmological examination may reveal extra ocular muscle imbalance as the causing factor of torticollis [16].

Ultrasonographic imaging is a useful diagnostic tool with important diagnostic and prognostic application [17]. This method is characterized by high sensitivity and specificity of $95.83 \%$ and $83.33 \%$, respectively. The ultrasonographic findings vary in accordance with different CMT stages [18].

Magnetic resonance imaging (MRI) is a modern radiologic examination with increasing role in CMT diagnosis. In a recent study MRI findings have been found to be correlated with histopathological findings [19].

\section{Differential Diagnosis}

Other nosological entities with similar clinical manifestations should be ruled out. Differential diagnosis includes Klippel -Fail syndrome, Grisel syndrome, osseous, neurological and psychiatric causes of torticollis, unilateral hearing difficulty which results in otogenic torticollis, neoplasms, infections and systematic diseases such as rheumatoid arthritis $[12,14,20]$.

\section{Treatment}

\section{Physical therapy}

Manual passive stretching of the sternocleidomastoid muscle before the age of 12 months is the most effective mode of physical therapy [21].

These exercises can be applied by parents after physical therapy. The one hand is lying on the child's head and the ipsilateral shoulder, while with the other lateral flexion of the head is applied together with rotation towards the opposite side [22].

At least two times a day, 10-15 stretches are performed, with time of dilatation rising up to thirty seconds [22]. Positive results are recorded, in a percentage bigger than $90 \%$ provided that the exercises are performed daily in the correct way. Recurrent rate is estimated as high as $2 \%$ [4]. Negative prognostic factors in the presence of a sternocleidomastoid mass are considered to be, the initial rotation of the head from the neutral position greater than 15 degrees and the beginning of the treatment after the first year of life [4].

In the conservative treatment, more frequent change of positions and turning of the head with stimuli of the environment, are included.

Introductory physical therapy includes heat application using paraphino-therapy and thermotherapy [21].

Iontophoresis implementation from 2 to 3 weeks of life respectively has been also proposed. The latter technique is used for resorption, organization and resolution the endomysial mass [21].

Microcurrent therapy appears to improve head tilting angle at supine (TA) and neck rotation range of motion to the affected side (RR) in infants with CMT as well [23].

Other physical therapy modalities for the SCI treatment include massage of tight neck muscles and subcutaneous tissues which increases pain-free range of motion, joint mobilization, myofascial release, craniosacral therapies and therapeutic taping [13,24,25].

An immediate effect on muscular imbalance in infants with CMT have been recorded with kinesiology taping [25].

Multiply adjustable torticollis brace have been also used in older children in a position of a soft overcorrection as an adjunct therapy [26].

\section{Botulinum toxin}

Botulinum toxin A injections have been reported for the treatment for all forms of cervical dystonia in few studies $[27,28]$. This method is safe and effective in children and adolescents with cerebral palsy especially in ambulatory patients [29]. It decreases spasticity to enable the manual stretching. Based on the same concept of muscle spasticity reduction these agents have been used in CMT by experienced practitioners for refractory to manual stretching cases [22].

A few adult cases of congenital muscular torticollis were successfully managed with botulinum toxin as well [30].

At the moment there is no adequate scientific evidence for the safety and efficiency of this modern treatment.

\section{Surgical treatment}

Surgical release may be considered in children older than 12-18 months of age with CMT resistant to conservative treatment or in case of facial asymmetry and plagiocephaly development [3,20,31] (Figure 2).

Surgical lengthening of the contracted SCM is mandatory in only $3 \%$ of the cases [2]. Surgery is highly recommended when a restriction of movement up to thirty degrees is present, as well in cases complicated with deformities of facial bones. A section of the clavicular insertion of the SCM is proposed, and an elongation in a Z-shape of its sternal insertion, in order to maintain its normal outline. Rarely, in neglected cases, a section of its mastoid insertion is also necessary $[2,12,14,15]$.

A potential complication of the surgical approach is an injury of the accessory nerve [12]. The rate of relapse is up to $1.2 \%$. In a review by excellent results were recorded $88.1 \%$, good results in $8.3 \%$, and fair to poor results in $3.6 \%$ of the patients surgically treated [26]. The age of the patient at presentation, ant the passive neck rotation range have been reported as the most important factors mandating surgical intervention [26,32].

The optimal time for surgical intervention is referred between 1

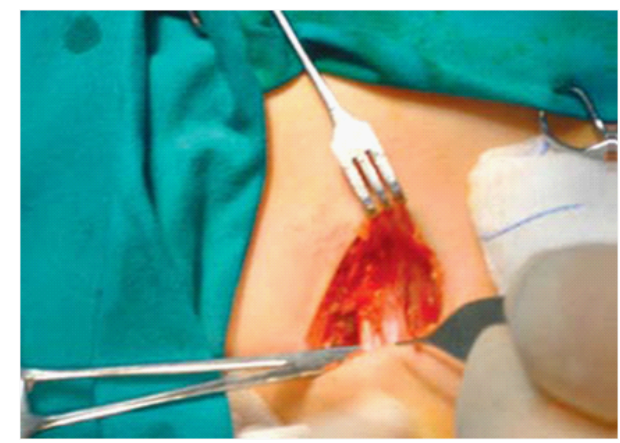

Figure 2: Tenotomy of the contracted sternocleidomastoid. (Courtesy of Gkiokas Andreas MD, PhD, $1^{\text {st }}$ Orthopaedic Department, General Children's Hospital, 'P. \& A. Kyriakou', Athens, Greece). 
and 4 years although favourable results have been also described for patients 10 years or older at the time of surgery [33]. For aged more than 6 years old, for safe results Chen and Co recommend bipolar release [33].

Postoperatively an intensive physical therapy program is applied including manual stretching of the sternocleidomastoid muscle for several months [14].

\section{Conclusion}

Treatment of CMT is primarily conservative. Positive results are recorded after manual stretching, in the biggest part.

Surgical release of the contracted SCM is imperative only in a small rate that conservative treatment fails, or in neglected cases that are accompanied by facial asymmetry. In mild deformities, a cross section of the SCM and a removal of $1-2 \mathrm{~cm}$ of its sternal and clavicular insertions are required.

In some serious cases a bipolar tenotomy of the SCM is needed. The major factor that determines the outcome of the surgery is the age of the patient.

\section{References}

1. Omidi-Kashani F, Hasankhani EG, Sharifi R, Mazlumi M (2008) Is surgery recommended in adults with neglected congenital muscular torticollis? A prospective study. BMC Musculoskelet Disord 9: 158

2. Cheng JC, Wong MW, Tang SP, Chen TM, Shum SL, et al. (2001) Clinical determinants of the outcome of manual stretching in the treatment of congenital muscular torticollis in infants. A prospective study of eight hundred and twentyone cases. J Bone Joint Surg Am 83-83A: 679-87.

3. Wei JL, Schwartz KM, Weaver AL, Orvidas LJ (2001) Pseudotumor of infancy and congenital muscular torticollis: 170 cases. Laryngoscope 111: 688-695.

4. Cheng JC, Chen TM, Tang SP, Shum SL, Wong MW, et al. (2001) Snapping during manual stretching in congenital muscular torticollis. Clin Orthop Relat Res : 237-244.

5. Tatli B, Aydinli N, Caliskan M, Ozmen M, Bilir F, et al. (2006) Congenital muscular torticollis: evaluation and classification. Pediatr Neurol 34: 41-44.

6. Hollier L, Kim J, Grayson BH, McCarthy JG (2000) Congenital muscular torticollis and the associated craniofacial changes. Plast Reconstr Surg 105: 827-835.

7. Chen MM, Chang HC, Hsieh CF, Yen MF, Chen TH (2005) Predictive model for congenital muscular torticollis: analysis of 1021 infants with sonography. Arch Phys Med Rehabil 86: 2199-2203.

8. Kim SN, Shin YB, Kim W, Suh H, Son HK, et al. (2011) Screening for the coexistence of congenital muscular torticollis and developmental dysplasia of hip. Ann Rehabil Med 35: 485-490.

9. Walsh JJ, Morrissy RT (1998) Torticollis and hip dislocation. J Pediatr Orthop 18: $219-221$

10. Davids JR, Wenger DR, Mubarak SJ (1993) Congenital muscular torticollis: sequela of intrauterine or perinatal compartment syndrome. J Pediatr Orthop 13: $141-147$

11. Thompson F, McManus S, Colville J (1986) Familial congenital muscula torticollis: case report and review of the literature. Clin Orthop Relat Res: 193196.

12. Tachdjian (1997) Clinical Pediatric Orthopedics: The Art of Diagnosis and Principles Management. Appleton \& Lange, USA

13. Freed S, Coulter-O'Berry C (2004) Identification and Treatment of Congenital Muscular Torticollis in Infants. JOP 16: 18.

14. Hefti F (2007) Congenital muscular torticollis, in Pediatric Orthopedics in Practice. Springer-Verlag: Berlin Heidelberg 117-120.
15. Staheli L (1998) Fundamentals of pediatric orthopedics. (2ndedn) LippincottRaven: Philadelphia, USA.

16. Canale ST, Griffin DW, Hubbard CN (1982) Congenital muscular torticollis. A long-term follow-up. J Bone Joint Surg Am 64: 810-816.

17. Cheng JC, Metreweli C, Chen TM, Tang S (2000) Correlation of ultrasonographic imaging of congenital muscular torticollis with clinical assessment in infants. Ultrasound Med Biol 26: 1237-1241.

18. Wang L, Zhang L, Tang Y, Qu L (2012) The value of high-frequency and color Doppler ultrasonography in diagnosing congenital muscular torticollis. BMC Musculoskelet Disord 13: 209.

19. Hwang JH, Lee HB, Kim JH, Park MC, Kwack KS, et al. (2012) Magnetic resonance imaging as a determinant for surgical release of congenital muscular torticollis: correlation with the histopathologic findings. Ann Rehabil Med 36: 320-327.

20. Wicart $P$ (2012) [Congenital torticollis]. Arch Pediatr 19: 335-339.

21. Petronic I, Brdar R, Cirovic D, Nikolic D, Lukac M, et al. (2010) Congenita muscular torticollis in children: distribution, treatment duration and out come. Eur J Phys Rehabil Med 46: 153-157.

22. Luther BL (2002) Congenital muscular torticollis. Orthop Nurs 21: 21-27.

23. Kim MY, Kwon DR, Lee HI (2009) Therapeutic effect of microcurrent therapy in infants with congenital muscular torticollis. PM R 1: 736-739.

24. Kang Y, Lu S, Li J, Meng F, Chang H (2011) Primary massage using one-finger twining manipulation for treatment of infantile muscular torticollis. J Altern Complement Med 17: 231-237.

25. Öhman AM (2012) The immediate effect of kinesiology taping on muscula imbalance for infants with congenital muscular torticollis. PM R 4: 504-508.

26. Cheng JC, Tang SP (1999) Outcome of surgical treatment of congenital muscular torticollis. Clin Orthop Relat Res : 190-200.

27. Jost WH, Hefter H, Stenner A, Reichel G (2013) Rating scales for cervical dystonia: a critical evaluation of tools for outcome assessment of botulinum toxin therapy. J Neural Transm 120: 487-496.

28. Hefter H, Kupsch A, Müngersdorf M, Paus S, Stenner A, et al. (2011) A botulinum toxin $A$ treatment algorithm for de novo management of torticollis and laterocollis. BMJ Open 1: e000196.

29. Papavasiliou AS, Nikaina I, Foska K, Bouros P, Mitsou G, et al. (2013) Safety of botulinum toxin $A$ in children and adolescents with cerebral palsy in a pragmatic setting. Toxins (Basel) 5: 524-536.

30. Bouchard M, Chouinard S, Suchowersky O (2010) Adult cases of congenita muscular torticollis successfully treated with botulinum toxin. Mov Disord 25: 2453-2456.

31. Sonmez K, Turkyilmaz Z, Demirogullari B, Ozen IO, Karabulut R, et al. (2005) Congenital muscular torticollis in children. ORL J Otorhinolaryngol Relat Spec 67: 344-347.

32. Cheng JC, Tang SP, Chen TM, Wong MW, Wong EM (2000) The clinical presentation and outcome of treatment of congenital muscular torticollis in infants--a study of 1,086 cases. J Pediatr Surg 35: 1091-1096.

33. Chen CE, Ko JY (2000) Surgical treatment of muscular torticollis for patients above 6 years of age. Arch Orthop Trauma Surg 120: 149-151. 